\title{
The following years
}

\begin{abstract}
Ifyou want a year of prosperity, grow grain. Ifyou want ten years of prosperity, grow trees. If you want a hundred years of prosperity, grow people.
\end{abstract}

(Chinese Proverb)

As we start a new year, our intention is to reassess our activities and focus on enlightening the future. On the second half of 2013, the Dental Press Journal of Orthodontics will complete 18 full years providing service to the science of Orthodontics. As adulthood nears, we begin our second year in control of this important information vehicle for the orthodontic science. We feel it is now time to reconsider our conducts and harvest in pursuit of the "grain" prosperity.

Through the collaboration of knowledgeable peers, who have turned into great friends throughout this challenging path, we have established goals that have been followed diligently. One of our main goals was to speed up the process between reviewing and publishing articles. Currently, the DPJO accepts one in four articles submitted. That parameter was set in the beginning of our journey to regulate our flow of articles and we accomplished a mean range of approximately 118 days between the submission process and a final decision to those articles that are approved. Our interval rate of acceptance and evaluation is similar to most major orthodontic journals worldwide.

Our belief is that an article denial should be disclosed as fast as possible, therefore the time frame between an article submission and rejection is, on average, three weeks and almost half of those articles receive an instant answer in less than a week. Usually, the rejected articles contain information that provides a less significant contribution to the innovation of the scientific orthodontic knowledge.

These mainly include clinical cases that reproduce procedures that have been extensively described in the past literature and non-original laboratory trials. The articles that pass through this initial selection go through a more detailed analysis by our reviewers, which may take up to two months on average to determine a final denial. The articles rejected on this phase are usually articles which ideas present prosperity, but the cultivating method impaired a proper harvest.

Besides working on speeding up the submission process, we have worked on reducing the interval between the approval of an article and its publication. At the end of 2011, the time frame between article approval and publication was 3 years; nowadays we have been able to reduce it to an average of 2 years.

Our goal is to publish all articles submitted in 2013 within 12 months from its final approval. A modest task to a journal that reaches adulthood and wishes to transcend decades in search and preservation of excellence, which is symbolized by the image of a strong tree on the proverb cited above.

As we approach adulthood, I would like to express my profound gratitude, on behalf of the Dental Press Publisher, to all the people responsible for the ongoing success of the Dental Press Journal of Orthodontics. It is my honor and pleasure to express thanks to our staff, authors, reviewers and editorial board for dedicating their precious time in contributing with the quality of science that we publish.

The DPJO foresees to continue spreading innovative orthodontic ideas with integrity and responsibility, which allows our readers to obtain prosperous orthodontic results day by day, grain by grain, tree by tree and by people's delighted smiles. After all, in contradiction with Woody Allen's thought; What kind of world would be wonderful if it wasn't for its own people?

David Normando

Editor-in-chief (davidnormando@hotmail.com)

\section{REFERENCES}

1. Normando D. Optimizing time and space. Dental Press J Orthod. 2012;17(2):6.

\section{Special thematic edition "Orthodontic treatment in adult patients"}

Dental Press Journal of Orthodontics (DPJO) is glad to announce the special edition with the theme "Orthodontic treatment in adult patients". Authors are invited to submit original unpublished articles related to this theme, following the publishing instructions in the end of the journal. The deadline for submitting articles is May 5th, 2013. All manuscripts will be analyzed through the peer-review system and the accepted ones will be published in the anniversary edition of SeptOct, 2013 of the DPJO. 